\title{
Community-Based Partnerships for Improving Chronic Disease Management
}

James Plumb

Thomas Jefferson University

Laura Carson Weinsten

Thomas Jefferson University

Rickie Brawer

Thomas Jefferson University

Kevin Scott

Thomas Jefferson University

Follow this and additional works at: https://jdc.jefferson.edu/fmfp

Part of the Community Health Commons, Family Medicine Commons, and the Translational Medical Research Commons

\section{Let us know how access to this document benefits you}

\section{Recommended Citation}

Plumb, James; Weinsten, Laura Carson; Brawer, Rickie; and Scott, Kevin, "Community-Based Partnerships for Improving Chronic Disease Management" (2012). Department of Family \& Community Medicine Faculty Papers. Paper 29.

https://jdc.jefferson.edu/fmfp/29

This Article is brought to you for free and open access by the Jefferson Digital Commons. The Jefferson Digital Commons is a service of Thomas Jefferson University's Center for Teaching and Learning (CTL). The Commons is a showcase for Jefferson books and journals, peer-reviewed scholarly publications, unique historical collections from the University archives, and teaching tools. The Jefferson Digital Commons allows researchers and interested readers anywhere in the world to learn about and keep up to date with Jefferson scholarship. This article has been accepted for inclusion in Department of Family \& Community Medicine Faculty Papers by an authorized administrator of the Jefferson Digital Commons. For more information, please contact: JeffersonDigitalCommons@jefferson.edu. 


\section{Community-based Partnerships for Improving Chronic Disease Management}

James Plumb, MD, MPH ${ }^{\mathrm{a}, \mathrm{b}}$, Lara Carson Weinstein, MD, MPH ${ }^{\mathrm{c}}$, Rickie Brawer PhD, MPH ${ }^{\mathrm{d}, \mathrm{e}}$ Kevin Scott MD

${ }^{\mathrm{a}}$ Professor - Department of Family and Community Medicine, Jefferson Medical College of Thomas Jefferson University

${ }^{\mathrm{b}}$ Director - Center for Urban Health Thomas Jefferson University and Hospital

${ }^{c}$ Assistant Professor - Department of Family and Community Medicine, Jefferson Medical College of Thomas Jefferson University

${ }^{\mathrm{d}}$ Associate Director - Center for Urban Health - Thomas Jefferson University and Hospital ${ }^{\mathrm{e}}$ Assistant Professor - Department of Family and Community Medicine, Jefferson Medical College of Thomas Jefferson University

${ }_{\mathrm{f}}^{\mathrm{f}}$ Instructor - Department of Family and Community Medicine, Jefferson Medical College of Thomas Jefferson University

The authors have nothing to disclose.

Keywords: chronic disease, community engagement, partnerships, chronic care model, diabetes, refugee, homeless 
${ }^{\mathrm{ab}}$ Corresponding author for $\quad{ }^{\mathrm{c}} \mathrm{Co}$-author $\quad{ }^{\mathrm{d}, \mathrm{e}} \mathrm{Co}$-author

proof and reprints:

\begin{tabular}{|l|l|l|}
\hline James Plumb MD, MPH & Lara Weinstein MD, MPH & Rickie Brawer PhD, MPH \\
Department of Family and & Department of Family and & Center for Urban Health \\
Community Medicine & Community Medicine & 1015 Chestnut - Suite 617 \\
Thomas Jefferson & Thomas Jefferson & Philadelphia, Pa 19107 \\
University & University & 1015 Walnut - Suite 401 \\
1015 Chestnut- Suite 617 & Philadelphia, PA 19107 & 215-955-2396 \\
james.plumb@jefferson.edu & lara.weinstein@ @efferson. & (215)955-8363 \\
(215)955-6340 & (215)955-7529(fax) & pital.org \\
(215)955-7529(fax) & & \\
\end{tabular}


${ }^{\mathrm{f}}$ Co-author

Kevin C. Scott MD
Department of Family and
Community Medicine
Thomas Jefferson
University
1015 Walnut - Suite 401
Philadelphia, PA 19107
(215)955-6340
(215)955-7529(fax)
kevin.c.scott@jefferson.edu

\section{Community-Based Partnerships for Improving Chronic Disease Management}

\section{Synopsis}

With the growing burden of chronic disease, the medical and public health communities are reexamining their roles and opportunities for more effective prevention and clinical 
interventions. The potential to significantly improve chronic disease prevention and impact morbidity and mortality from chronic conditions is enhanced by adopting strategies that incorporate a social ecology perspective, realigning the patient-physician relationship, integrating population health perspectives into the chronic care model, and effectively engaging communities using established principles of community engagement.

\section{Introduction}

Chronic diseases such as heart disease, cancer, hypertension, stroke, and diabetes now account for $80 \%$ of deaths in the United States (US) and $75 \%$ of health care costs. ${ }^{1}$ In 2005 , $44 \%$ of all Americans had at least 1 chronic condition and $13 \%$ had 3 or more. By 2020, an estimated 157 million US residents will have 1 chronic condition or more. ${ }^{1}$ With this growing burden of chronic disease, the medical and public health communities are reexamining their roles and envisioning innovative partnership opportunities for more effective interventions for chronic disease prevention and management at a population level.

The potential to significantly improve chronic disease prevention and impact morbidity and mortality from chronic conditions is enhanced by adopting strategies that integrate population health and social ecological perspectives into the chronic care model, realigning the patient-physician relationship, and effectively engaging communities.

\section{The Expanded Chronic Care Model}

From a health care system perspective, the Chronic Care Model (CCM), as developed

originally by Wagner, ${ }^{2}$ identifies the essential elements that encourage high-quality care for individuals suffering from chronic disease. These elements are the health system, self 
management support, delivery system design, decision support, clinical information systems, and the individuals' communities. This Model was later refined to incorporate more specific concepts in each of the above six elements - patient safety in health systems, cultural competency and care management in delivery system design, care coordination in health system and clinical information systems, and an emphasis on leveraging community policies and community resources to address individual needs and care goals.

Because the CCM is geared to clinically oriented systems and difficult to use for broader prevention and health promotion practices, Barr and colleagues ${ }^{3}$ proposed the Expanded Chronic Care Model (ECCM) in 2003 to include elements of the population health promotion field so that broadly-based prevention efforts, recognition of the social determinants of health, and enhanced community participation could also be integrated into the work of health system teams as they seek to address chronic disease issues. The ECCM includes three additional components in terms of community resources and policies. These include: building healthy public policy, creating supportive environments, and strengthening community action. ${ }^{3}$ These interrelated components and relationships are shown in FIGURE 1

The ECCM represents a shift from primary- and hospital-based care focused on illness and disability to community-oriented services that focus on the prevention of illness and disability before they have a chance to occur. This shift is a vital aspect of responsible and accountable healthcare management in today's climate of healthcare reform with a strong emphasis on ensuring that community members are involved in planning for new services. ${ }^{3}$

\section{Realigning the Patient-Physician Relationship}


Because chronic disease management is complex, it also requires a new view of the patient-provider relationship in addition to enhanced community-based partnerships.

Collaborative care is a partnership paradigm that credits patients with an expertise that is similar in importance to the expertise of professionals. ${ }^{4}$

According to Holman and Loring, health care can be delivered more effectively and efficiently if patients are full partners in the process. When acute disease was the primary cause of illness, patients were generally inexperienced and passive recipients of medical care, particularly since longitudinal follow-up was not required for these episodes. Now that chronic disease has become the principal medical problem for so many, patients must become partners in the care process, contributing their knowledge, preferences, and personal/social contexts at each decision or action level. ${ }^{5}$

\section{Rationale for Community Partnerships in Chronic Disease Management}

Chronic conditions are rooted not only in physiological processes, but also in sociocultural and political contexts. However, medical providers and programs primarily consider chronic conditions at the individual or intrapersonal level. Chronic conditions are difficult to manage, much less “cure," through a series of disconnected interventions such as brief office visits, public health announcements, government funded programs, individual service programs or the establishment of community advocacy groups. A more comprehensive approach to address root determinants of these chronic conditions is required, one involving community engagement in defining the problem and developing partnerships to identify and implement effective and sustainable solutions and management strategies 
According to Green and colleagues, ${ }^{6}$ past public health efforts focused primarily on communicable disease. However, chronic diseases exist within the context of a much wider array of lifestyle and social circumstances, each of which impacts the cause and course of disease. Thus, a comprehensive, multilevel, multi-partner approach is required to develop the capacity to implement effective chronic illness prevention and health promotion programs that link traditional healthcare and socio-environmental and political efforts. ${ }^{6}$ The healthy community model for the 21 st century should bridge disease prevention and management efforts that are often developed, implemented and evaluated in "silos." It should also connect health promotion and management efforts across chronic diseases that often share the same underlying root causes of disease, such as smoking, overweight/obesity, and limited physical activity.

\section{Social Ecology Theory and Community Partnerships}

The Social Ecology $\operatorname{Model}^{7}$ of health promotion provides an important framework for integrating community partnerships and chronic disease management. According to social ecology theory, the potential to change individual risk behavior is considered within the social and cultural context in which it occurs. ${ }^{8}$ The social ecology model describes several levels of influence which are critically interrelated and which must be recognized and addressed to effect positive health change, including: intrapersonal factors, interpersonal factors, institutional and organizational factors, community factors, public policies and broader structural or social factors. ${ }^{7}$ Within the context of the Social Ecology Model, individuals, social support systems, community organizations, informal networks, and public policy leaders must be engaged and collaborate for successful health promotion and chronic disease management. 
One example of the social ecology model is the Building Community Support for Diabetes Care (BCS) of the Robert Wood Johnson Foundation. ${ }^{9}$ The BCS required that projects build community supports for diabetes care through clinic-community partnerships, by addressing four key areas: 1) working with existing services, encouraging use of these services and enhancing access to them; 2) working together to identify gaps and create new programs, services, or policies that complement existing services; 3) providing leadership and a forum to raise awareness about diabetes and create consumer demand for resources and supports; and 4) providing a forum for community input and participation. ${ }^{9}$ Examples of BCS interventions by ecological level are found in Table 1.

Brownson et. al. ${ }^{9}$ conclude that BCS projects using partnership approaches show promise for building community support for diabetes care. Chronic illness care and patient selfmanagement for diabetes and other chronic conditions will benefit from continued support for implementation and evaluation of partnerships to build community supports for selfmanagement.

\section{Community Engagement and Community Capacity Building}

According to the Centers for Disease Control and Prevention (CDC), ${ }^{10}$ community engagement is defined as the process of working collaboratively with groups of people who are affiliated by geographic proximity, special interests, or similar situations with respect to issues affecting their well- being. It is helpful to consider the concepts of "community" and "capacity building" to help shape the community engagement process. First, the term, "community," is a complex and fluid concept that needs to be defined. Some useful factors to consider when defining a community include: socioeconomics, demographics, health status indices, ethnic and 
cultural characteristics, geographic boundaries, community norms, formal and informal power and authority figures, stakeholders, communication patterns, and existing assets and resources. ${ }^{3}$

Second, when considering a community collaborative approach to addressing specific health concerns, it is important to also consider the process of "capacity building." Capacity building accounts for current resources available to a particular group as well as additional knowledge, skills and resources that may need to be made available to community members in order for them to participate in meaningful community engagement. Capacity building is more complex and time consuming than approaching superficial community engagement in a manner that simply seeks community "buy-in" to a predetermined intervention. However, the effort spent on capacity building will be much more likely to ensure a viable program in the long run (i.e., sustainability). For example, true capacity building in a coalition with diverse membership whose focus is to address diabetes management and prevention might include: diabetes training for community leaders and lay health workers; assistance with survey development; programs to improve coalition members' understanding of community based education; facilitating the identification of community goals and potential strategies to achieve those goals; and strengthening relationship networks with grant writing skills and with government program planners and funders.

The CDC / Agency for Toxic Substances and Disease Registry (ATSDR) Committee for Community Engagement ${ }^{10}$ has developed and refined principles for community engagement that incorporate key concepts to "assist public health professionals and community leaders interested in engaging the community in health decision making and action." These principles are summarized in Table 2. The principles of engagement can be used by people in a range of roles, from the program funder who needs to know how to support community engagement to the 
researcher or community leader who needs hands-on, practical information on how to mobilize the members of a community to partner in research initiatives.

\section{Community Based Partnerships: Local and National Case Examples}

\section{Jefferson's Department of Family and Community Medicine and Center for Urban Health}

Thomas Jefferson University’s (TJU) Department of Family and Community Medicine (DFCM) is focusing on delivering a new model of care, which provides state-of-the-art, comprehensive primary care in a variety of settings, from community to hospital, and engages communities in improving health indices. This new model of care, built on DFCM and TJU Hospitals' (TJUH) resources and well-established links to community partnerships, integrates the best of family medicine, community, and public health principles and practice. The DFCM faculty, fellows, residents and staff are committed to participating more actively in reducing inequalities in health, creating environments supportive of health, strengthening community action, building healthy public policy, and reorienting health services.

Jefferson's Center for Urban Health (CUH), directed by a DFCM faculty member, builds on the work of the DFCM and multiple TJUH community outreach activities. The mission of the Center is to improve the health and well being of Philadelphia citizens throughout the lifespan by marshalling the resources of TJUH, TJU and its DFCM, and partnering with community organizations and neighborhoods. The Center's goal is to improve the health status of individuals and targeted communities and neighborhoods through a multi-faceted initiative, the 
ARCHES Project, which focuses on six domains/themes including: 1) Access and Advocacy; 2)

Research, Evaluation, and Outcomes Measurement; 3) Community Partnerships and Outreach; 4) Health Education, Screening and Prevention Programs; 5) Education of Health Professions Students and Providers; and 6) Service Delivery Systems Innovation.

Through the ARCHES Project, the Center's many partners include schools, homeless shelters, senior centers, faith-based communities, and other broad-based collaborative efforts that recognize neighborhood economic, social, and physical environments as underlying determinants of health and disease. In addition, the Center undertakes more extensive assessments in partnership with community-based organizations to create programs that reflect community need, voice and culture. Projects are planned and evaluated individually based on established baselines set from existing data; information gleaned from key stakeholders through interviews, focus groups and surveys that address critical attitudes, beliefs, and behaviors; and assessment of community assets/resources such as human, economic and social capital. Importantly, project planning and evaluation are driven by community members rather than the Center, which provides technical expertise, linkages, and other support throughout the ongoing iterative processes.

Specifically, the Jefferson CUH facilitates academic-community partnerships by serving as a bridge between TJU/TJUH and urban neighborhoods to improve health outcomes through the following mechanisms: 1) facilitating collaborations around research, community projects, program planning/implementation and evaluation; 2) strengthening the capacity of the Philadelphia neighborhoods to address community identified needs; and 3) initiating and monitoring sustainable, collaborative interventions. 
Additional DFCM/CUH community partnerships are summarized in Table 3, including the Center for Refugee Health, Jeff H.O.P.E, ${ }^{11,12}$ Wellness Center, Pathways to Housing ${ }^{13-1715,16}$ and the Stroke, Hypertension and Prostate Education Intervention Team. ${ }^{18}$ The JOINED-UP Program, Community Asthma Prevention Program of Philadelphia ${ }^{19}$ and Healthy Eating Active Living Convergence Partnership ${ }^{20}$ are described in detail below to provide examples of successful, community-driven local and national efforts. These programs illustrate the opportunity to engage with communities and community organizations to enhance chronic disease management. Without this engagement, vulnerable populations would not have the advantage of chronic disease prevention, detection or management.

The Job Opportunity Investment Network Education on Diabetes in Urban Populations (JOINED-UP) Project

The Job Opportunity Investment Network Education on Diabetes in Urban Populations (JOINED-UP) was built on a partnership between CUH and the Philadelphia Federation of Neighborhood Centers (FNC). ${ }^{21}$ Founded in 1906, FNC is an umbrella organization for 15 community-based organizations, with deep roots in the community in the tradition of Jane Adams' Settlement House Movement. ${ }^{21}$ The Federation's member agencies provide services to more than 100,000 children, adults and families per year and have developed relationships with multiple generations of families. ${ }^{21}$

JOINED-UP was a diabetes and obesity healthy lifestyle education program that was embedded into a Green Jobs workforce development training program held at two FNC member agencies that targeted low-skilled, low-resourced residents in Philadelphia. As part of the comprehensive job training program, participants in the program were required to attend six 
Healthy Lifestyle workshops that were based on principles of the chronic disease self management model and that used a "patient" case study (whose attributes were created by program participants) as a means to encourage sharing of real life experiences related to incorporating healthier behaviors onto daily life. Participants met individually with a professional health educator to review screening/survey results, discuss personal health concerns, and create a personal action plan. Motivational Interviewing (MI) techniques guided this discussion. A Certified Diabetes Educator (CDE) met individually with individuals whose screening results indicated pre-diabetes and provided information about diabetes, as well as suggestions for risk reduction. The $\mathrm{CDE}$ counseled diagnosed diabetics about managing diabetes and preventing complications. A key component of the JOINED-UP program was facilitating patient activation and linkage to primary care. This provided an opportunity to engage and educate patients in a trusted setting to improve interaction between patients and their primary care providers.

The JOINED-UP program exemplifies a community-hospital outreach partnership that educated participants about diabetes prevention and control and linked them to community resources including primary healthcare providers. The JOINED-UP project has resulted in a number of successful outcomes, including: 1) Integrating a diabetes prevention and management program into a workforce development program is a feasible and effective method of recruiting and engaging African-American men in a disease self management program; 2) Directly linking the management of one's health to attaining and retaining a job, enhances the motivation of clients to better manage their chronic health conditions because they develop a clear understanding that one must stay healthy to secure and keep a job; 3) Providing healthy lifestyle education in a familiar community center rather than a healthcare facility helps to build trust between health educators and other members of the healthcare team and their client partners. 
"Going to where men are" is crucial to effective engagement; 4) Providing wrap-around services (i.e., job training, transportation, child care, emergency assistance, housing assistance, etc.) in a central location where disease self management programming and support are also delivered helps keep clients engaged in the self management program as well as the job training program, and allows clients to incorporate disease management into their day-to-day routines. This strategy offers synergistic rather than merely additive benefit; 5) Recognizing the high prevalence of pre-diabetes (44\%) provides an opportunity to impact further progression of disease in participants; and 6) providing healthy lifestyle education as part of a workforce development program can be an important factor in improving the health of children and families.

\section{Community Asthma Prevention Program of Philadelphia}

The Community Asthma Prevention Program of Philadelphia (CAPP) ${ }^{19}$ provided community-based education for asthmatic children; however, this community-driven intervention was also designed to create community lay asthma experts who could sustain prevention and disease management efforts.

The CAPP, based on the You Can Control Asthma@-validated curriculum developed by Georgetown University, was initiated in Philadelphia in 1997 by the Children's Hospital of Philadelphia (CHOP) through a cooperative agreement with the U.S. Department of Health and Human Services. ${ }^{22}$ This program involved a collaborative of more than twenty communitybased organizations, including primary care providers, hospitals, health care insurers, faith-based institutions, recreation centers, and schools, that combined science with community assets, interests and preferences to address poorly controlled asthma among children. This evidencebased, multi-faceted, comprehensive program included opportunities for parents/caregivers and 
children to learn about asthma self-management and control, education for primary care providers, and provided home visits conducted by trained lay-health-educators to assess environmental triggers. Community involvement ensured that interventions were acceptable and accessible to the community, as well as integrated with other community efforts related to asthma management.

Educational programs for asthmatic children and their caregivers were held in community sites such as schools, daycare centers and churches, and were taught by trained peer educators including parents of asthmatic children as well as asthmatic teenagers and college students. Students received free asthma devices such as peak flow meters, and mattress and pillow covers to reduce environmental triggers. Overall more than 3,500 members of the community contributed to and participated in the program over a four year period. ${ }^{23}$ In a study of 267 participants, knowledge, quality of life and asthma control significantly improved compared to pre-program measures. ${ }^{23}$ Moreover and notably, these gains were retained for at least one year. ${ }^{23}$ In addition, workshops for school personnel were conducted for classroom teachers, health and physical education teachers, coaches and school nurses to convey information about asthma symptoms and treatment and the impact of asthma on school performance and attendance.

Finally, CAPP and CHOP, through the Controlling Asthma in American Cities Project, offered three levels of primary care provider education based on NHBLI guidelines and the needs of practitioners and their staffs. Using a modified Physician Asthma Care Education (PACE) curriculum, Level One focused on asthma knowledge and patient-provider communication. Level Two facilitated practice system changes by creating physician and nurse asthma champions in practices, integrating support from CAPP's clinical coordinator through 
monthly case discussions and teleconferences, and using an Asthma Toolbox and patient education materials designed by literacy experts. In Level Three educational programs, quality improvement methods were integrated into practices through site-specific interventions.

In order to build a more robust system of coordinated services, CAPP's efforts have been linked to other asthma education programs through the efforts of Philadelphia Allies Against Asthma (PAAA) ${ }^{24}$ The Child Asthma Link Line developed by PAAA connects asthmatic children seen in Philadelphia's pediatric Emergency Departments or referred by schools to CAPP's community and school based programs. The CAPP and PAAA programs demonstrate how multi-sector community involvement helps to create realistic approaches to disease management, reduce barriers to care, and reduce duplicative efforts by bridging and integrating multiple existing efforts aimed at improving health outcomes and reducing health disparities, thereby leveraging available community resources and assets.

Reducing or eliminating health disparities such as those seen with the burden of asthma morbidity among different ethnic and racial groups remains a challenge. Primary care interventions that are linked with community-based interventions that address family, social and behavioral factors is essential in meeting this challenge. Comprehensive systematic approaches that connect diverse community partners, raise awareness and knowledge about health concerns, and support policies addressing fragmented systems that affect health including health insurance, school systems, and housing are needed to support and improve on the results of traditional primary care efforts. Current efforts to reduce obesity and its underlying root causes provide the context for the final case study.

\section{Healthy Eating Active Living Convergence Partnership}


Obesity is a complex health issue, and as such, requires complex solutions that involve diverse individuals and institutions across multiple levels of society and that leverage publicprivate partnerships. More than one-third of adults and $17 \%$ of children in the United States are obese. $^{25}$ Obesity is a risk factor for many health conditions including heart disease, stroke, hypertension, Type 2 diabetes, some cancers, liver and gall bladder disease sleep apnea, respiratory problems, osteoarthritis, fertility problems and mental health conditions. Like asthma, obesity cannot be managed by interventions focused at the individual level alone. Scientists, the medical community, government, schools, business and other community partners must coordinate responses designed to reverse this growing epidemic. Efforts to reduce and control obesity are currently being implemented at the local, state and national level and involve partners who may have little or no tradition of working together on health issues. These nontraditional partners include societal sectors such as food supply and distribution systems, school food systems and policies, food outlets such as supermarkets and corner stores, health care, urban planning and zoning departments, transportation, recreation and parks departments, and community based organizations such as the YMCA, bicycle coalitions, neighborhood centers and faith-based institutions among many others.

In 2006, a collaboration of funders (the California Endowment, Kaiser Permanente, the Kresge Fundation, Nemours, the Robert Wood Johnson Foundation, and the W.K.Kellogg Foundation) created the Healthy Eating Active Living Convergence Partnership. ${ }^{20}$ These national organizations were funding initiatives focused on healthy eating and active living as strategies to address overweight and obesity and were interested in developing a more coordinated approach for improving healthy food and physical activity norms and environments. The CDC provided technical assistance and Policy Link, a national research and action institute devoted to economic 
and social equity, served as the program director for the Healthy Eating Active Living Convergence Partnership. The Prevention Institute, a non-profit organization that promotes and advocates for policies, organizational practices, and collaborative efforts that improve health and the quality of life, provides policy research, analysis and strategic support for the Healthy Eating Active Living Convergence Partnership. The Convergence Partnership is committed to promoting and leveraging work across multiple fields and sectors to advance knowledge, resource-sharing, and policy and environmental change that will help build a national movement towards healthy people in healthy places. The Healthy Eating Active Living Partnership supports each partners' efforts and seeks to build new internal and external relationships to build synergy across multiple disciplines and to strengthen local, regional and national policy and system change efforts that support fresh, local healthy food and safe places to play and be active. $^{20}$ The Convergence Partnership has developed a 10-point vision to promote healthy eating and active living. This vision is summarized in Table $4 .:^{20}$

Healthcare organizations and providers play an important role in reducing obesity. Primary care providers need to adopt and implement standard practices for routine BMI screening and counseling that supports healthier food choices and physical activity at every visit. Hospitals and other healthcare employers need to set an example for other employers by promoting physical activity such as taking the stairs and improving food choices in cafeterias and vending machines. Primary care providers and hospitals should also support breastfeeding initiation, duration and exclusivity, one of the five target areas identified by the CDC's StateBased Nutrition and Physical Activity Program to Prevent Obesity and Other Chronic Diseases (NPAO). ${ }^{25}$ Finally, physicians and other health care providers can refer patients to community 
organizations that promote healthy eating and physical activity, and can advocate for system and policy changes that make healthy choices the easier choices for their patients.

\section{Conclusion}

With the growing burden of chronic disease, the medical and public health communities are reexamining their roles and exploring opportunities for more effective prevention and clinical interventions. There is growing recognition of the need to address the underlying root causes/contributing factors that cross multiple chronic diseases and to integrate the "silos" in which chronic diseases are addressed. A social ecology approach to chronic disease calls for the development of new collaborations between the traditional medical system (outpatient physicians, emergency care, and inpatient facilities) and economic development, housing, zoning, and access to healthy and affordable food. As professionals and citizens ${ }^{26}$, providers can become directly involved in providing technical expertise and/or advocating in a variety of ways for changes in social polices that effect health ${ }^{27}$. The expanded chronic care model provides a foundation to explore these expanded roles and to operationalize the social ecology approach. The established principles of community engagement detail a methodology to work with communities to organize a more comprehensive approach to chronic disease prevention and management.

To improve chronic disease management, physicians and the health systems in which they work need to understand the principles of community engagement and proactively join in efforts underway in communities in which they serve. Multiple examples of community engagement have been provided highlighting the impact that can be realized through collaboration with agencies which interface with populations at levels that are not traditionally 
"health" related. This impact has been most evident in improving chronic disease management and outcomes in diabetes, asthma, obesity and hypertension.

Future directions for research include rigorous testing of the Expanded Chronic Care Model from a cost-effectiveness perspective, mixed-method evaluation strategies that involve community members, such as participatory action research, and evaluation of processes designed to enhance coordination between community-based programs and health care providers through data sharing and collaborative planning. 


\section{Table 1: Examples of BCS interventions by ecological level}

\begin{tabular}{|c|c|}
\hline Ecological Level & BCS Interventions \\
\hline Individual & $\begin{array}{l}\text { Diabetes education classes, supermarket tours, case management, } \\
\text { community walking maps, cooking demonstrations }\end{array}$ \\
\hline Family, friends and peers & Family diabetes curriculum, support groups, peer led education classes \\
\hline Systems/organizations & $\begin{array}{l}\text { Office staff training to enhance capacity to support diabetes self- } \\
\text { management, physician prescription pads for referrals to walking clubs, } \\
\text { creation of health care performance goals }\end{array}$ \\
\hline Community/Policy & $\begin{array}{l}\text { Advocacy training for project workers, securing indoor spaces for physical } \\
\text { activity, diabetes materials in public libraries, presentations to community } \\
\text { organizations to increase awareness of diabetes, improved selection of fresh } \\
\text { produce at local markets }\end{array}$ \\
\hline
\end{tabular}


Table 2: Principles of Community Engagement ${ }^{10}$

\begin{tabular}{|c|c|}
\hline Principle & Key elements \\
\hline Set Goals & $\begin{array}{l}\text { - } \text { Clarify the purposes/goals of the engagement effort } \\
\text { - } \quad \text { Specify populations and/or communities }\end{array}$ \\
\hline Study Community & $\begin{array}{ll}\text { - } & \text { Economic conditions } \\
\text { - } & \text { Political structures } \\
\text { - } & \text { Norms and values } \\
\text { - } & \text { Demographic trends } \\
\text { - } & \text { History } \\
\text { - } & \text { Experience with engagement efforts } \\
\text { - } & \text { Perceptions of those initiating the engagement activities }\end{array}$ \\
\hline Build Trust & $\begin{array}{l}\text { - } \text { Establish relationships } \\
\text { - Work with the formal and informal leadership } \\
\text { - Seek commitment from community organizations and leaders } \\
\text { - Create processes for mobilizing the community }\end{array}$ \\
\hline Encourage self-determination & $\begin{array}{l}\text { - Community self-determination is the responsibility and right of all } \\
\text { people } \\
\text { - No external entity should assume that it can bestow on a community } \\
\text { the power to act in its own self-interest }\end{array}$ \\
\hline Establish partnerships & - $\quad$ Equitable partnerships are necessary for success \\
\hline Respect diversity & $\begin{array}{l}\text { - Utilize multiple engagement strategies } \\
\text { - Explicitly recognize cultural influences }\end{array}$ \\
\hline $\begin{array}{l}\text { Identify community assets and } \\
\text { develop capacity }\end{array}$ & $\begin{array}{l}\text { - View community structures as resources for change and action } \\
\text { - Provide experts and resources to assist with analysis, decision- } \\
\text { making, and action } \\
\text { - Provide support to develop leadership training, meeting facilitation, } \\
\text { skill building }\end{array}$ \\
\hline Release control to the community & - Include as many elements of a community as possible \\
\hline
\end{tabular}




\begin{tabular}{|l|ll|}
\hline & $\bullet$ & Adapt to meet changing needs and growth \\
\hline Make a long-term commitment & $\bullet \begin{array}{l}\text { Recognize different stages of development and Provide ongoing } \\
\text { technical assistance }\end{array}$ \\
\hline
\end{tabular}

Table 3: Examples of Jefferson community partnerships facilitating chronic disease

management

\begin{tabular}{|c|c|c|c|c|}
\hline Program & Community Partners & Description & Outcomes & Funding Sources \\
\hline Jeff HOPE & $\begin{array}{l}\text { Salvation Army } \\
\text { Resources for Human } \\
\text { Development } \\
\text { Prevention Point } \\
\text { Acts of the Apostles II } \\
\text { Bethesda Project }\end{array}$ & $\begin{array}{l}\text { Jefferson Medical student } \\
\text { outreach program } \\
\text { Provides free health care, } \\
\text { health education and social } \\
\text { advocacy services to homeless } \\
\text { or otherwise medically } \\
\text { underserved individuals }\end{array}$ & $\begin{array}{l}\text { - } 2000 \text { visits per year } \\
\text { Screened } 300 \text { men } \\
\text { for CV disease, }{ }^{12} \\
\text { colorectal cancer, } \\
\text { prostate cancer, and } \\
\text { hepatitis C }\end{array}$ & $\begin{array}{ll}\text { - } & \text { Student fundraising } \\
\text { - } & \text { TJUH contribution } \\
\text { - } & \text { American Assoc. of } \\
\text { Medical Colleges } \\
\text { - } \quad \text { Caring Community } \\
\text { grants } \\
\text { - TJUH Women's } \\
\text { Board } \\
\text { - Civic Foundation }\end{array}$ \\
\hline Welln & $\begin{array}{l}\text { Project H.O.M.E. } \\
\text { Wellness Center } \\
\text { Ridge Avenue } \\
\text { Business Association } \\
\text { Women Against } \\
\text { Abuse } \\
\text { Pro-Act } \\
\text { Council for } \\
\text { Relationships }\end{array}$ & $\begin{array}{l}\text { Primary medical care, } \\
\text { behavioral health care, } \\
\text { nutrition education, } \\
\text { rehabilitative services, case } \\
\text { management, and peer-led } \\
\text { health promotion. } \\
\text { Direct linkage to supportive } \\
\text { housing, neighborhood-based } \\
\text { affordable housing, economic } \\
\text { development, access to } \\
\text { employment opportunities; } \\
\text { adult and youth education }\end{array}$ & $\begin{array}{ll} & 800 \text { visits/year } \\
- & \text { Implementation of } \\
& \text { diabetes registry }\end{array}$ & $\begin{array}{ll}- & \text { Independence } \\
\text { BlueCross } \\
\text { Foundation } \\
\text { - } \quad \text { Medicaid Managed } \\
\text { Care }\end{array}$ \\
\hline $\begin{array}{l}\text { Pathways to } \\
\text { Housing }\end{array}$ & $\begin{array}{l}\text { Pathways to Housing- } \\
\text { PA }\end{array}$ & $\begin{array}{ll}\text { - } & \text { Housing First model which } \\
\text { ends chronic homelessness for } \\
\text { individuals with serious } \\
\text { mental illness }{ }^{13,14} \\
\text { - } \quad \text { Scattered site permanent } \\
\text { supportive housing } \\
\text { - Trans-disciplinary care } \\
\text { management team }{ }^{15} \\
\text { - } \quad \text { Novel integrated care program }\end{array}$ & $\begin{array}{ll}- & \text { Chronic disease } \\
\text { registry }{ }^{16} \\
\text { - } & \text { Ongoing tracking of } \\
\text { standard health } \\
\text { indicators } \\
\text { - } \\
\text { Integrated health } \\
\text { record } \\
\text { - } \begin{array}{l}\text { Medication } \\
\text { management and e- }\end{array}\end{array}$ & $\begin{array}{ll}\text { Housing: } \\
\text { Philadelphia Office } \\
\text { of Supportive } \\
\text { Housing } \\
\text { - } \quad \text { Intensive care } \\
\text { management: } \\
\text { Philadelphia } \\
\text { Department of } \\
\text { Behavioral health }\end{array}$ \\
\hline
\end{tabular}




\begin{tabular}{|c|c|c|c|c|}
\hline & & $\begin{array}{l}\text { through a unique partnership } \\
\text { with the DFCM } \\
\text { Dit }\end{array}$ & $\begin{array}{ll}\text { prescribing } \\
\text { On-site adult } \\
\text { vaccines } \\
\end{array}$ & \\
\hline $\begin{array}{l}\text { Center for } \\
\text { Refugee Health }\end{array}$ & $\begin{array}{l}\text { Nationalities Service } \\
\text { Center (NSC) } \\
\text { Lutheran Family and } \\
\text { Children's Services } \\
\text { Hebrew Immigrant } \\
\text { Aid Society }\end{array}$ & $\begin{array}{l}\text { Partnership facilitates } \\
\text { communication between the } \\
\text { resettlement agencies and } \\
\text { DFCM to assist refugees } \\
\text { navigate through the } \\
\text { healthcare system (labs, } \\
\text { imaging, specialists, } \\
\text { pharmacies, etc.) }\end{array}$ & $\begin{array}{l}\text { Since } 2009, \text { more } \\
\text { than } 700 \text { refugees } \\
\text { have received } \\
\text { comprehensive } \\
\text { screening and } \\
\text { follow-up at DFCM }\end{array}$ & $\begin{array}{ll}- & \text { Barra Foundation } \\
- & \text { Pennsylvania } \\
& \text { Refugee } \\
& \text { Coordination Center }\end{array}$ \\
\hline $\begin{array}{l}\text { SHAPE-IT } \\
\text { Stroke, } \\
\text { Hypertension and } \\
\text { Prostate } \\
\text { Evaluation and } \\
\text { Intervention Team }\end{array}$ & $\begin{array}{l}\text { DFCM } \\
\text { Center for Urban } \\
\text { Health } \\
\text { Philadelphia } \\
\text { Department of Health } \\
\text { Health Promotion } \\
\text { Council } \\
\text { Community Partners }\end{array}$ & $\begin{array}{l}\text { Reduce the incidence of stroke } \\
\text { and morbidity and mortality } \\
\text { from prostate cancer high risk } \\
\text { AA men } \\
\text { - } \quad \text { Development of Project } \\
\text { Advisory Council (PAC) }\end{array}$ & 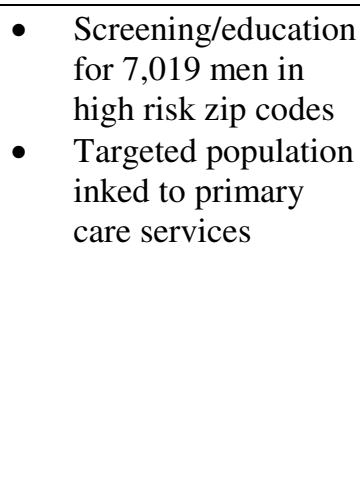 & $\begin{array}{l}\text { - Pennsylvania } \\
\text { Department of } \\
\text { Health }\end{array}$ \\
\hline
\end{tabular}




\section{Table 4 - Convergence Partnership Vision}

Safe neighborhoods, communities, and buildings support physical activity as part of everyday life;

Fresh, local and healthy food is available and affordable in all communities and neighborhoods;

Healthy foods and beverages are promoted in grocery and other food stores, restaurants, and entertainment venues;

Schools offer and promote healthy foods and beverages to students;

Schools promote healthy physical activities and incorporate them throughout the day, including before and after school;

Workplaces and employers offer and promote access to healthy foods and beverages and opportunities for physical activity;

Health care organizations and providers promote healthy eating and active living in their own institutional policies and in their clinical practices;

Government and the private sector support and promote healthy eating and active living environments;

Organizations, institutions and individuals that influence the information and entertainment environments share responsibility for and act responsible to promote healthy eating and active living

Childcare organizations, including preschool, afterschool and early childhood settings, offer and promote only healthy foods and beverages to children and provide sufficient opportunities for, 
and promote physical activity

Adapted From: Barr, V., Robinson, S.,Marin-Link, B., Underhill, L., Dotts, A., Ravensdale, D., \& Salivaras, S. (2003). The Expanded Chronic Care Model: An Integration of Concepts and Strategies from Population Health Promotion and the Chronic Care Model. Hospital Quarterly, 7(1), 73-

82.

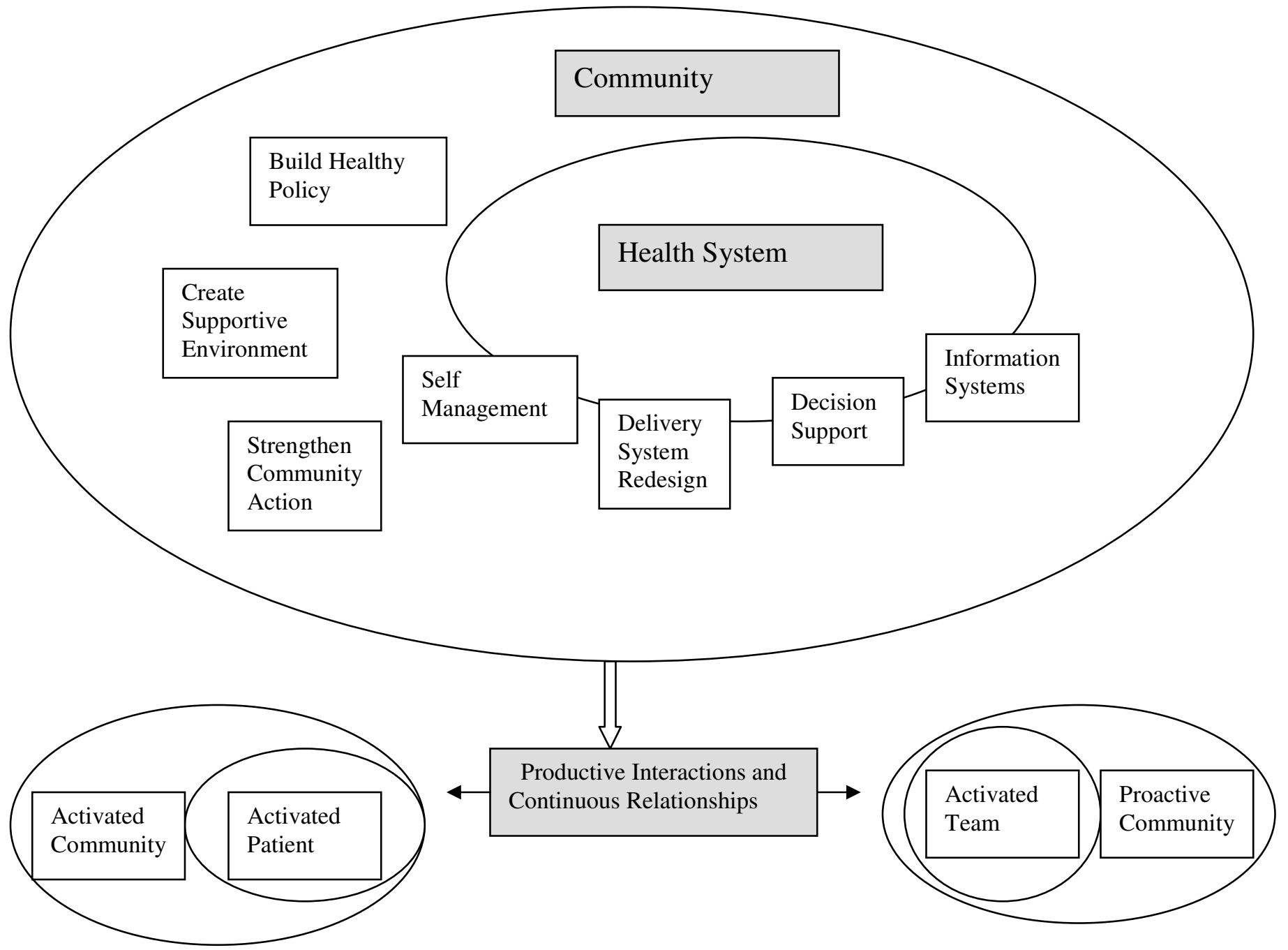




\section{References}

1. Tackling the burden of chronic diseases in the USA. Lancet 2009;373(9659):185.

2. Wagner EH, Austin BT, Davis C et al. Improving chronic illness care: translating evidence into action: interventions that encourage people to acquire self-management skills are essential in chronic illness care. Health Aff 2001;20(6):64-78.

3. Barr VJ, Robinson S, Marin-Link B et al. The expanded Chronic Care Model: an integration of concepts and strategies from population health promotion and the Chronic Care Model. Hosp Q 2003;7(1):73-82.

4. Bodenheimer T, Lorig K, Holman $\mathrm{H}$ et al. Patient self-management of chronic disease in primary care.see comment. JAMA 2002;288(19):2469-75.

5. Holman H, Lorig K. Patients as partners in managing chronic disease. Br Med J 2000;320(7234):526-7.

6. Green L, Daniel M, Novick L. Partnerships and coalitions for community-based research. Public Health Rep 2001;116(SUPPL. 1):20-31.

7. McLeroy KR, Bibeau D, Steckler A et al. An ecological perspective on health promotion programs. Health Educ Q 1988;15(4):351-77.

8. Goodman RM, Wandersman A, Chinman M et al. An Ecological Assessment of Community-Based Interventions for Prevention and Health Promotion: Approaches to Measuring Community Coalitions. Am J Community Psychol 1996;24(1):33-61. 
9. Brownson CA, O'Toole ML, Shetty G et al. Clinic-community partnerships: A foundation for providing community supports for diabetes care and self-management. Diabetes Spectr 2007;20(4):209-14.

10. Principles of Community Engagement: Edition 2. Clinical and Translational Science Awards Consortium Community Engagement Key Function Committee Task Forse on the Principles of Community Engagement. 2011;11-7782. Available at http://www.atsdr.cdc.gov/communityengagement/index.html. Accessed July 26, 2011.

11. Hemba K, Plumb JD. JeffHOPE: The Development and Operation of a Student-Run Clinic. Journal of Primary Care and Community Health 2011;2(3):167.

12. Kim DH, Daskalakis C, Plumb JD et al. Modifiable cardiovascular risk factors among individuals in low socioeconomic communities and homeless shelters. Fam Commun Health 2008;31(4):269-80.

13. Tsemberis S, Stefancic A. Pathways' Housing First Program. NREPP: SAMHSA's National Registry of Evidence-Based Programs and Practices. Rockville, MD: United States Department of Health and Human Services, Substance Abuse and Mental Health Service Administration. 2008. Available at http://homeless.samhsa.gov/channel/housing-first-447.aspx Accessed 7/23/2011. Accessed December 16, 2011.

14. Tsemberis S, Gulcur L, Nakae M. Housing First, consumer choice, and harm reduction for homeless individuals with a dual diagnosis. Am J Public Health 2004;94(4):651-6. 
15. Weinstein LC, Henwood BF, Cody J et al. Transforming Assertive Community Treatment into an Integrated Care System: The Role of Nursing and Primary Care Partnerships. Journal of the American Psychiatric Nurses Association 2011.

16. Weinstein LC, Henwood BF, Matejkowski J et al. Moving from street to home: Health Status of Entrants to a Housing First Program. Journal of Primary Care and Community Health 2011;2(1).

17. Henwood BF, Weinstein LC, Tsemberis S. Creating a medical home for homeless persons with serious mental illness. Psychiatr Serv 2011;62(5):561-2.

18. Weinstein LC, Plumb JD, Brawer R. Community engagement of men. Prim Care Clin Off Pract 2006;33(1):247-59.

19. Community Asthma Prevention Program (CAPP). Available at http://www.chop.edu/service/community-asthma-prevention-program-capp/home.html. Accessed December 16, 2011.

20. Lee V, Mikkelsen L, Srikantharajah J et al. Promising Strategies for Creating Healthy Eating and Active Living Environments. 2008.

21. Philadelphia Federation of Neighborhood Centers. Available at. Accessed on December $16,2011$.

22. Bryant-Stephens T. Asthma disparities in urban environments. J Allergy Clin Immunol 2009;123(6):1199-206.

23. Bryant-Stephens T, Li Y. Community asthma education program for parents of urban asthmatic children. J Natl Med Assoc 2004;96(7):954-60. 
24. Rosenthal MP, Butterfoss FD, Doctor LJ et al. The coalition process at work: Building care coordination models to control chronic disease. Health Promot Pract 2006;7(2 Suppl):117S-

25. Obesity - Halting the Epidemic by Making Health Esier. 2011. Centers for Disease Control and Prevention, At a Glance 2011.

http://www.cdc.gov/chronicdisease/resources/publications/AAG/obesity.htm. Accessed

December 22, 2011.

26. Gruen RL, Pearson SD, Brennan TA. Physician citizens - public roles and professional responsibilities. JAMA 2006; 291(1):94-98

27. Woolf S. Social policy and health policy. JAMA 2000; 11: 1166-1169 